\title{
Radionuclide Imaging of Musculoskeletal Infection
}

\author{
Christopher J. Palestro ${ }^{1,2 *}$ and Charito Love ${ }^{3}$ \\ ${ }^{1}$ Professor of Nuclear Medicine and Radiology, Albert Einstein College of Medicine, Bronx, New York. ${ }^{2}$ Chief \\ Division of Nuclear Medicine and Molecular Imaging, North Shore Long Island Jewish Health System, Manhasset \\ and New Hyde Park, New York, palestro@lij.edu. ${ }^{3}$ Research Scientist, Division of Nuclear Medicine and Molecular \\ Imaging, North Shore Long Island Jewish Health System, Manhasset and New Hyde Park, New York
}

\begin{abstract}
Radionuclide imaging studies are routinely used to evaluate patients suspected of having musculoskeletal infection. Three-phase bone imaging is readily available, relatively inexpensive, and very accurate in the setting of otherwise normal bone. Labeled leukocyte imaging should be used in cases of "complicating osteomyelitis" such as prosthetic joint infection. This test also is useful in clinically unsuspected diabetic pedal osteomyelitis as well as in the neuropathic joint. It is often necessary, however, to perform complementary bone marrow imaging, to maximize the accuracy of labeled leukocyte imaging. In contrast to other regions in the skeleton, labeled leukocyte imaging is not useful for diagnosing spinal osteomyelitis. At the moment, gallium is the preferred radionuclide procedure for this condition and is a useful adjunct to magnetic resonance imaging. FDG-PET likely will play an important role in the evaluation of musculoskeletal infection, especially spinal osteomyelitis, and may replace gallium imaging for this purpose.
\end{abstract}

Key words: Musculoskeletal infection, osteomyelitis, bone scintigraphy, labeled leukocytes, gallium, FDG-PET

\section{INTRODUCTION}

The diagnosis of musculoskeletal infection can be clinically challenging and imaging procedures are routinely performed as part of the diagnostic workup. Although there are several radionuclide tests from which to choose, it is important to realize that no one test is optimal for every situation. This article reviews the principles, indications, and limitations of radionuclide imaging studies available for diagnosing musculoskeletal infection.

\section{Radionuclide Imaging Procedures}

\section{Three-Phase Bone Scintigraphy}

Bone scintigraphy is performed with technetium-99m labeled diphosphonates, usually methylene diphosphonate (MDP), the uptake of which depends on blood flow and the rate of new bone formation. The three-phase bone scan consists of the flow or perfusion phase, acquired immediately after tracer injection, followed immediately by an image of the region of interest, the blood pool or soft-tissue phase. The third, or bone, phase consists of images performed two to four hours later. The classic appearance of osteomyelitis is focal hyperperfusion, focal hyperemia, and focal bone uptake (Fig. 1). Bone scintigraphy is widely available, relatively inexpensive, easily performed and rapidly completed, and extremely sensitive. With an accuracy of more than 90\%, 3-phase bone scintigraphy is the nuclear medicine test of

\footnotetext{
${ }^{*}$ Author for correspondence
} 
choice for diagnosing osteomyelitis in bones not affected by underlying conditions (Maurer et al., 1981; Schauwecker, 1992; Palestro and Torres, 1997). Abnormalities on bone scans, however, reflect the rate of new bone formation in general and not infection specifically. Consequently tumors, fractures, orthopedic hardware, and the neuropathic joint can all result in a positive three-phase bone scan in the absence of infection, and in these circumstances, because of decreased specificity, the bone scan is less useful (Schauwecker, 1992; Palestro and Torres, 1997).

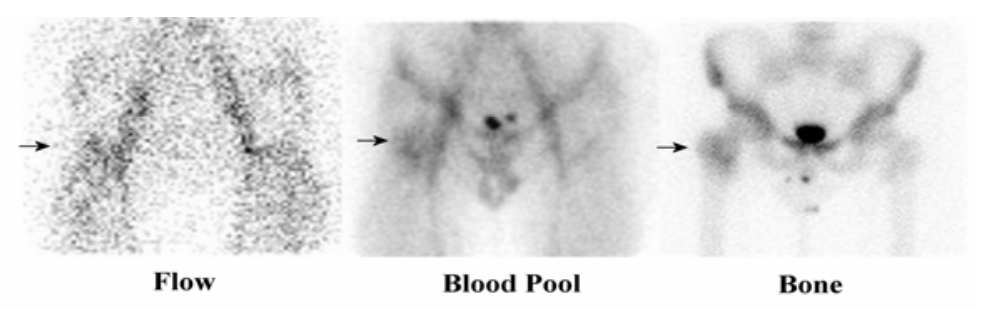

Figure 1 - Osteomyelitis of the right femur. There is focal hyperperfusion focal hyperemia, and focally increased bone uptake in the proximal right femur (arrows). This is the classic appearance of osteomyelitis on three phase bone scintigraphy

\section{Gallium Scintigraphy}

Several factors govern uptake of this tracer in inflammation and infection. About $90 \%$ of circulating gallium is in the plasma and nearly all of it is transferrin bound. Increased blood flow and increased vascular membrane permeability result in increased delivery and accumulation of transferrin-bound gallium at inflammatory foci. Gallium also binds to lactoferrin, which is present in high concentrations in most infections. Direct uptake of gallium by certain bacteria has been observed in-vitro. Siderophores, small molecular weight chelates produced by bacteria, have a high affinity for gallium. The siderophore-gallium complex is presumably transported into the bacterium, where it remains until phagocytosed by macrophages. Although some gallium is transported bound to leukocytes, it is important to note that even in patients with few or no circulating leukocytes, this agent can detect infection with good sensitivity. Imaging is usually performed 18-72 hours after injection and is often performed in conjunction with radionuclide bone imaging. Although reliable when clearly positive or negative, the study is frequently equivocal and the overall accuracy of bone/gallium imaging ranges between about $60 \%$ and $80 \%$ (Fig. 2). The less than ideal imaging characteristics of gallium and the need for two isotopes with multiple imaging sessions over several days are additional disadvantages to the procedure (Hoffer, 1980; Palestro, 1994).

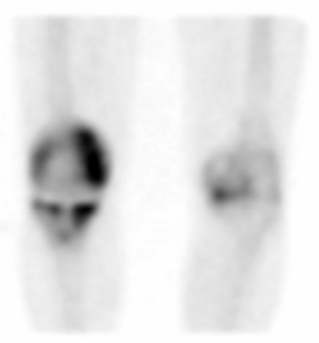

Bone

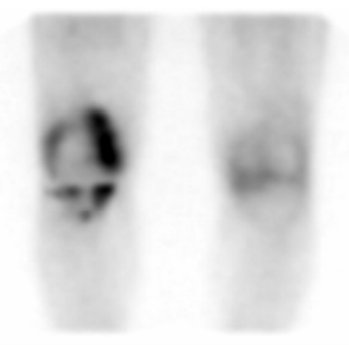

Gallium

Figure 2 - The spatial distribution and relative intensity of periprosthetic activity around the left hip arthroplasty on the bone and gallium images are virtually identical and the combined study is equivocal for infection. A significant limitation of bone/gallium imaging is the frequency with which the results are equivocal 


\section{In-Vitro Labeled Leukocytes}

A variety of in-vitro leukocyte labeling techniques have been used; the most commonly employed procedures make use of indium-111 oxyquinolone (oxine) or technetium-99m-HMPAO (exametazime). A total circulating white count of at least $2000 / \mathrm{uL}$ is needed to obtain satisfactory images. The majority of white cells labeled usually are neutrophils, and the procedure is, therefore, most useful for identifying neutrophil-mediated inflammatory processes, such as bacterial infections. The procedure is less useful for those illnesses in which the predominant cellular response is other than neutrophilic (Fineman et al., 1989; Palestro et al., 1991; Palestro et al., 1992; Love and Palestro, 2004; Vicente et al., 2005).

Labeled leukocyte imaging is the radionuclide procedure of choice for diagnosing so-called complicating osteomyelitis (Palestro and Torres, 1997). Although they do not usually accumulate at sites of increased bone mineral turnover in the absence of infection, labeled leukocytes do accumulate in the bone marrow. The normal distribution of hematopoietically active bone marrow in adults, generally assumed to be confined to the axial and proximal appendicular skeletons, actually is quite variable. Systemic diseases such as sickle cell and Gaucher disease produce generalized alterations in marrow distribution, while fractures, orthopedic hardware, and the neuropathic joint cause localized alterations. Thus it is not always possible to determine if an area of activity on a labeled leukocyte image represents infection or atypically located, but otherwise normal, marrow and it is often necessary to perform technetium-99m sulfur colloid bone marrow imaging (Fig. 3) (Palestro et al., 2006). Both leukocytes and sulfur colloid accumulate in the bone marrow; leukocytes also accumulate in infection, sulfur colloid, however, does not (Feigin et al., 1976). The combined study is positive for infection when activity is present on the labeled leukocyte image without corresponding activity on the sulfur colloid marrow image (Fig. 4) (Palestro et al., 2006). The overall accuracy of combined leukocyte/marrow imaging is approximately 90\% (Mulamba et al., 1983; King et al., 1990; Palestro et al., 1990; Palestro et al., 1991; Seabold et al., 1991; Palestro et al., 1992; Achong et al., 1994; Palestro et al., 1998; Joseph et al., 2004; Love et al., 2004).

\section{In-Vivo Labeled Leukocyte Imaging}

There are significant limitations to the in-vitro leukocyte labeling procedure. It is labor intensive, not always available, and involves direct handling of blood products. Considerable effort, therefore, has been devoted to the search for in-vivo methods of labeling leukocytes, including peptides and antigranulocyte antibodies (Love and Palestro, 2003). None of these in-vivo methods, which have met with mixed results, are approved for use in the United States.

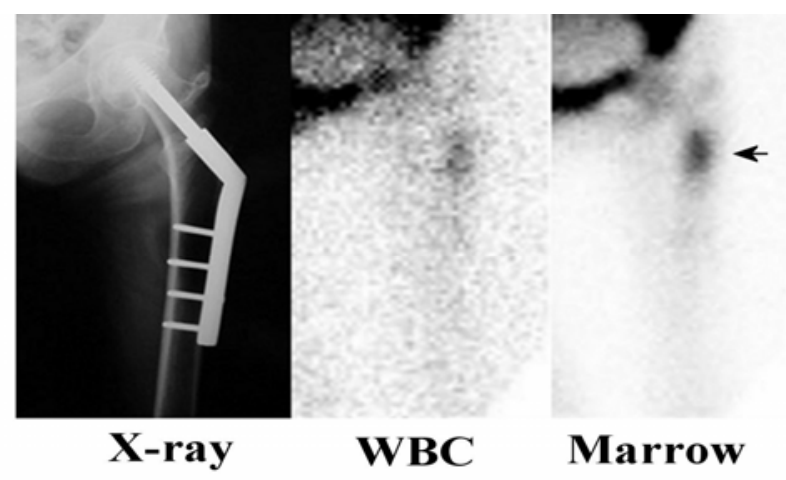

Figure 3 - Uninfected orthopedic hardware. There is focally increased activity in the proximal left femur on the labeled leukocyte study. Interpreted alone, it is not possible to exclude osteomyelitis. An identical focus (arrow) is present on the bone marrow image, however, which indicates that the activity on the labeled leukocyte image represents marrow, not infection 


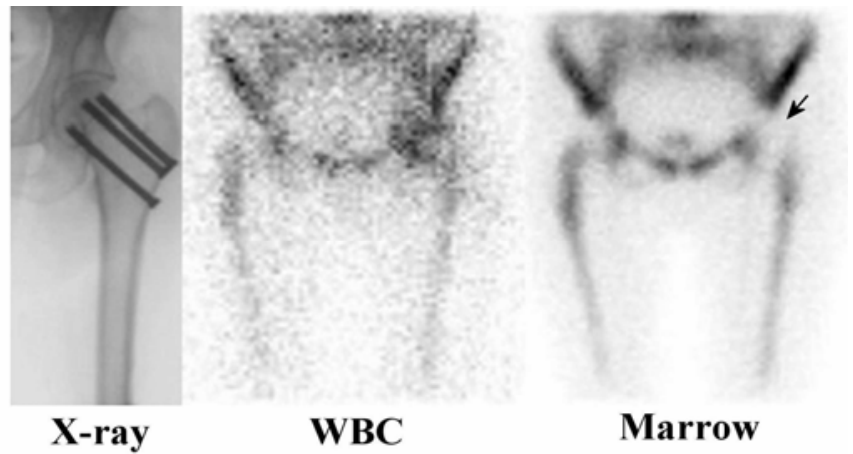

Figure 4 - Infected orthopedic hardware. There is slightly increased activity in the left hip on the labeled leukocyte image, which could easily be interpreted as normal. There is no corresponding activity on the bone marrow image (arrow), and the combined study is unequivocally positive for infection

\section{FDG-PET}

Fluorine-18- fluorodeoxyglucose (FDG) is transported into cells via glucose transporters, and is phosphorylated to ${ }^{18} \mathrm{~F}-2$ '-FDG-6 phosphate but is not metabolized. The uptake of FDG is related to the cellular metabolic rate as well as to the number of glucose transporters available (Bell et al., 1993; Pauwels et al., 1998; Zhuang and Alavi, 2002). Activated inflammatory cells, such as neutrophils, lymphocytes, monocytes, and macrophages, demonstrate increased expression of glucose transporters and in inflammatory conditions, the affinity of these glucose transporters for deoxyglucose may be increased by cytokines and growth factors (Kubota et al., 1992; Pauwels et al., 1998; Mochizuki et al., 2001; Paik et al., 2004).

FDG-PET has several potential advantages over conventional nuclear medicine tests. Results are available within 30-60 minutes of tracer administration. Normal bone marrow has only a low glucose metabolism under physiological conditions, which may facilitate the distinction of inflammatory cellular infiltrates from hematopoietically active marrow. Degenerative bone changes usually show only faintly increased FDG uptake compared to osteomyelitis. FDG-PET images are not affected by metallic implant artefacts and have a distinctly higher spatial resolution than images obtained with single photon emitting tracers. Finally FDG is less expensive then the combinations of radiolabeled leukocyte/bone marrow/bone scan multimodality imaging techniques (Gemmel et al., 2006).

Several studies support the value of FDG for diagnosing musculoskeletal infection but prospective investigations focused on particular indications are necessary to accurately define its role in musculoskeletal infection (Guhlmann et al., 1998; Sugawara et al., 1998, Kalicke et al., 2000; De Winter et al., 2001; Schiesser et al., 2003).

\section{Radiolabeled Antibiotics}

An interesting approach to diagnosing musculoskeletal infection makes use of radiolabeled antibiotics Presumably the radiolabeled antibiotic is incorporated and metabolized by the bacteria present in the infectious focus resulting in accurate and specific localization of the infection. The most extensively studied of these compounds is technetium-99mciprofloxacin (Infecton ${ }^{\mathrm{TM}}$, DraxImage, Kirkland, Quebec Canada). Published results have been variable however (Sonmezoglu et al., 2001; Sarda et al., 2002; De Winter et al., 2004; Gemmel et al., 2004). At the present time, this agent is available only on an investigational basis.

\section{Indications}

\section{Spinal osteomyelitis}

Spinal osteomyelitis, which has a predilection for the elderly, may result from bacteremia or direct inoculation of bacteria into the spine. Usually confined to the vertebral body and intervertebral 
disc, the posterior elements are involved in up to twenty percent of cases (Love et al., 2000). Magnetic resonance imaging (MRI) with an accuracy of about $90 \%$ is the imaging procedure of choice for diagnosing spinal osteomyelitis (Modic et al., 1985). It permits early diagnosis of infection, and provides direct visualization of the spinal cord, subarachnoid space, extradural soft tissues, and spinal column, without intrathecal contrast. There are limitations to this test, however. Severe degenerative disc disease, with edema-like granulation changes in the endplates and in the superior and inferior aspects of the disc, can mimic infection on MRI. The test is sensitive to motion and patients who cannot remain still may not be suitable candidates for imaging. In patients with certain implants, such as pacemakers and cardiac valves, the test is contraindicated. In these situations, as well as when MRI is nondiagnostic, or at odds with the clinical impression, nuclear medicine studies are a useful alternative. The current radionuclide procedure of choice for diagnosing spinal osteomyelitis is combined bone/gallium imaging, with results comparable to those of MRI. In addition to enhancing the specificity of the bone scan, gallium imaging is useful for detecting the abscesses that often accompany this entity (Lisbona et al., 1993; Palestro and Torres, 1997; Hadjipavlou et al., 1998; Love et al., 2000). There are data that suggest that if gallium tomography, or SPECT, is performed, the bone scan is not needed (Fig. 5) (Love et al., 2000).

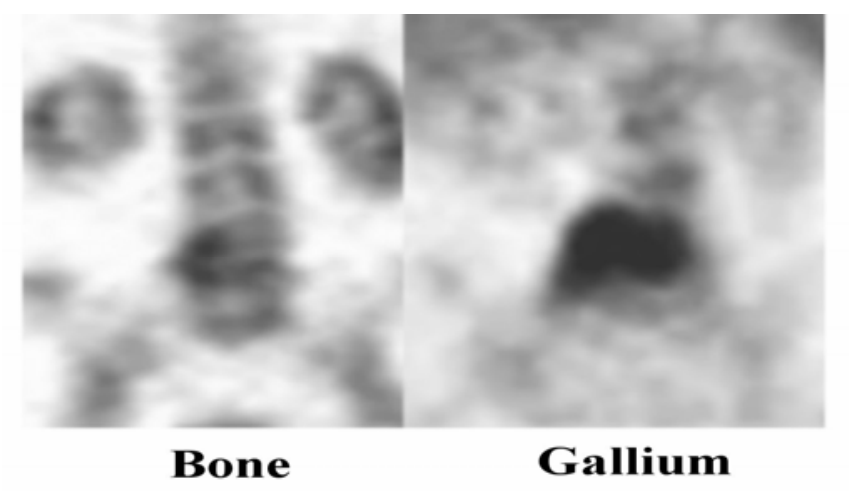

Figure 5 - Lumbar spine osteomyelitis. Coronal bone tomogram demonstrates increased tracer uptake along the right lateral aspect of L4 and L5, along with loss of the invertebral disc space, consistent with spinal osteomyelitis. Coronal gallium tomogram demonstrates that the abnormality is much more extensive with the infection extending into the adjacent soft tissues on the right

FDG-PET is a promising alternative to bone and gallium imaging for diagnosing spinal osteomyelitis (Fig. 6). It may be especially useful for distinguishing true infectious spondylodiscitis from severe granulation-type degenerative disc disease, a differentiation that is not always easily made with MRI (Stumpe et al., 2002). One group of investigators reported that FDG-PET was superior to MRI in patients who had a history of surgery and suffered from high-grade infection in combination with paravertebral abscess formation and in those with low-grade spondylitis or discitis (Gratz et al., 2002). 


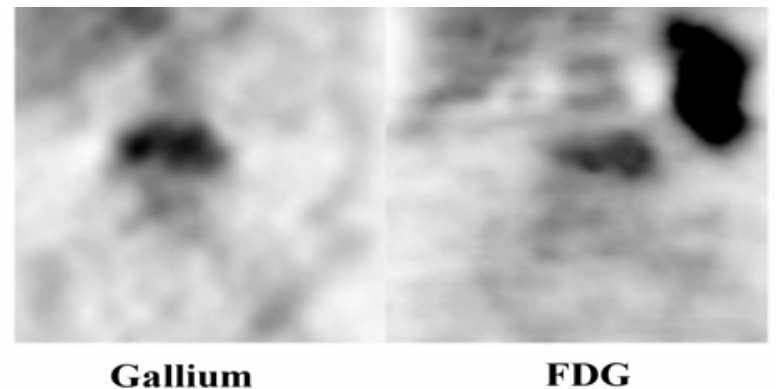

Figure 6 - Gallium and FDG-PET studies both show intense activity in the lower lumbar spine of a patient with L3-L4 spinal osteomyelitis

In 57 patients, including 27 with metallic hardware, suspected of having spinal infection after spinal surgery, the sensitivity, specificity, and accuracy of FDG-PET were $100 \%, 81 \%$, and $86 \%$, respectively. Among 30 patients without implants, there were 2 false positive results: both in patients who had undergone surgery less than six months prior to imaging. Among 27 patients with spinal implants, there were six false positive results. Sensitivity, specificity and accuracy were not significantly different between the group of patients that had surgery within 6 months before the FDG-PET and the group who had surgery more than 6 months before FDG-PET imaging. The specificity was $65 \%$ in the group with spinal implants and $92 \%$ in the group without. The overall accuracy, $86 \%$, of FDG-PET in this prospective study was good; the negative predictive value, $100 \%$, was excellent (De Winter et al., 2003).

In contrast to other sites in the skeleton, labeled leukocyte imaging is not useful for diagnosing spinal osteomyelitis as $50 \%$ or more of all cases appear as areas of nonspecific decreased or absent activity (photopenia) on white cell images. This photopenia is associated with numerous conditions, besides infection, including tumor, infarction and Paget's disease (Palestro et al., 1991).

\section{Diabetic Foot Infections}

The most common complication in the diabetic forefoot is the mal perforans ulcer, accounting for more than $90 \%$ of all cases of diabetic pedal osteomyelitis. Many patients with pedal osteomyelitis present without systemic illness and lack obvious clinical signs and symptoms other than the ulcer, and imaging studies are often used to confirm the diagnosis (Palestro and Tomas, 2000).

Radiographs should be the initial imaging study performed because they may provide the diagnosis and because they give an overview of the anatomy and any underlying complicating structural changes. In many cases however, more advanced imaging is needed and either labeled leukocyte imaging or MRI can be performed (Fig. 7). A meta-analysis of the literature with determination of weighted averages for each modality showed that radiographs had a weighted average sensitivity of $54 \%$ and $80 \%$ specificity, threephase bone scan had an average of $91 \%$ sensitivity and $46 \%$ specificity, labeled white cell studies had $88 \%$ sensitivity and $82 \%$ specificity, and MR imaging had $92 \%$ sensitivity and $84 \%$ specificity (Wrobel and Connolly, 1998).

Approximately $5 \%$ of diabetics with neuropathy develop a neuropathic or Charcot joint, usually involving the tarsal or tarsometatarsal joints. The most common radiographic finding is a Lisfranc fracture-dislocation with eburnation and fragmentation of the tarsometarsal joints.

Ultimately, massive bony sclerosis, osteophytosis, frank destruction of bones and joints, and osseous debris occur. It can be difficult to distinguish the destruction of neuro-arthropathy from that of superimposed infection (Palestro and Tomas, 2000).

The dramatic bony changes of the Charcot joint invariably result in a positive three-phase bone scan even in the absence of infection (Palestro and Tomas, 2000). Labeled leukocyte accumulation in the uninfected neuropathic joint also occurs, but this problem can be overcome by performing complementary bone marrow imaging (Fig. 8) (Palestro et al., 1998). 


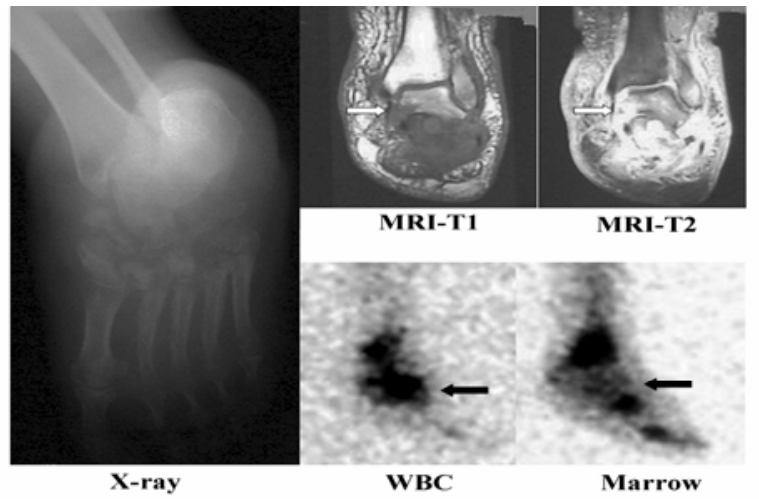

Figure 7 - Osteomyelitis of a Charcot joint. Radiograph shows soft tissue swelling and bony destruction consistent with Charcot joint. MRI shows changes consistent with soft tissue inflammation and possible bony involvement (arrows). On the labeled leukocyte image, there is increased activity in the distal tibia and in the hind foot (arrow). The tibial activity is also present on the marrow image, but the hind foot activity is not (arrow). Analysis of the amputation specimen revealed hematopietically active marrow in the distal tibia and osteomyelits of the hindfoot

Diagnosing complications of the diabetic foot is challenging. For pedal osteomyelitis the most useful studies are MRI and labeled leukocyte scintigraphy. Besides availability and experience, the information desired will govern the choice of imaging study to be performed. MRI has the obvious advantages of providing excellent anatomic detail and resolution of both bones and soft tissues. Labeled leukocyte imaging may be more sensitive for detecting clinically unsuspected pedal osteomyelitis and is useful for monitoring response to medical therapy, and evaluating the neuropathic joint (Newman et al., 1991; Newman et al., 1992; Palestro et al., 1998; Palestro and Tomas, 2000).

There are too few data available at the present time to assess the role of FDG-PET in diabetic foot infections (Keidar et al., 2005).

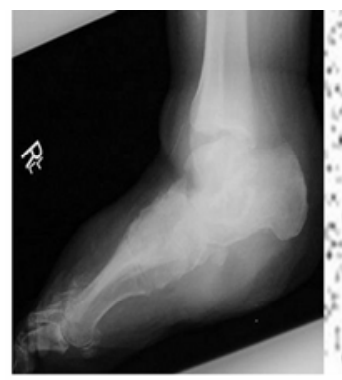

X-ray

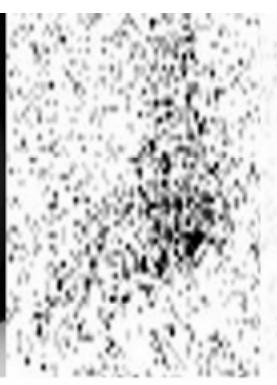

WBC

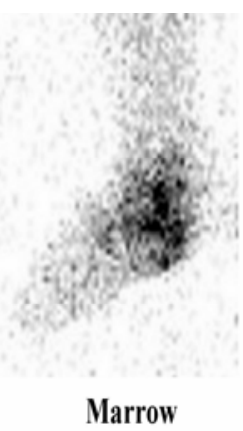

Marrow

Figure 8 - Uninfected Charcot joint. X ray shows soft tissue and bony changes consistent with Charcot joint. There is increased activity in the Charcot joint on the labeled leukocyte image. The distribution of activity is the same on the bone marrow image. Thus the activity on the labeled leukocyte image is due to hematopoietically active bone marrow, not to infection

\section{Prosthetic Joint Infection}

Some complications of joint replacement surgery, such as dislocation and fracture, are readily diagnosed and treated. Differentiating infection from aseptic loosening is more difficult, however, because the clinical presentation of, and the 
histopathologic changes in, both entities are remarkably similar (Love et al., 2001).

A significant number of cases of aseptic loosening are due to an inflammatory/ immune reaction against the prosthesis itself. A synovial-like pseudomembranous structure develops at the cement/bone interface. The cellular composition of the pseudomembrane is varied: histiocytes are seen most frequently (95\% of specimens), followed by giant cells (80\%), and lymphocytes and plasma cells $(25 \%)$. Neutrophils are present in less than $10 \%$ of the cases. Particulate debris, produced by component wear and fragmentation, presumably attracts and activates tissue phagocytes present around the prosthesis. This debris is impervious to regular enzymatic destruction, leading to repeated, unsuccessful, attempts at phagocytosis, which in turn stimulate proinflammatory cytokine and proteolytic enzyme secretion that damage bone and cartilage and activate immune cells. The heightened inflammatory response leads to osteolysis, resulting in loss of supporting osseous tissues and, eventually, prosthetic loosening (Love et al., 2001).

The rate of infection following primary implantation is about $1 \%$ for hip and $2 \%$ for knee prostheses. The rate of infection following revision surgery is somewhat higher: about $3 \%$ for hip and $5 \%$ for knee replacements. About one third of these infections develop within three months, another third within one year, and the remainder more than one year after surgery. Histopathologically, the inflammatory reaction accompanying the infected prosthesis is similar to that present in aseptic loosening, with one important difference: neutrophils, which are usually absent in aseptic loosening, are invariably present in infection (Love et al., 2001).

Differentiating aseptic loosening from infection is extremely important because the treatment of these two entities is very different. The patient with an aseptically loosened device usually undergoes a single stage revision arthroplasty requiring only one hospital admission. The treatment of the infected prosthesis is more complicated, requiring a two-stage procedure; the infected prosthesis is removed, the patient receives a course of antimicrobial therapy, and eventually undergoes a revision arthroplasty (Love et al., 2001).

Nonspecific markers of inflammation such as the erythrocyte sedimentation rate and C-reactive protein level may be elevated in both loosening and infection. Plain radiographs are neither sensitive nor specific and cross-sectional imaging modalities, such as CT and MRI, can be limited by hardware induced artifacts (Love et al., 2001). Joint aspiration with gram stain and culture is considered the definitive diagnostic test; its sensitivity, however, is variable, ranging from $28 \%$ to $92 \%$. Its specificity is more consistent, ranging from $92 \%$ to $100 \%$ (Fehring and Cohen, 1996; Lachiewicz et al., 1996; Cheung et al., 1997).

Radionuclide imaging, which reflects physiologic rather than anatomic changes, and is not affected by metallic hardware, plays an important role in the evaluation of prosthetic joint infection. The current imaging procedure of choice for evaluating suspected joint replacement infection is combined leukocyte/marrow imaging with an overall accuracy ranging from 88\%-98\% (Mulamba et al., 1983; Palestro et al., 1990; Palestro et al., 1991; Joseph et al., 2001; Love et al., 2004). Although inflammation may be present in both the infected and aseptically loosened device, neutrophils, which are invariably present in infection, are usually absent in aseptic loosening. Because the success of labeled leukocyte imaging is directly dependent on the presence of a neutrophil response, this critical histological difference between infection and aseptic loosening accounts for the high sensitivity and specificity of leukocyte/marrow imaging for diagnosing prosthetic joint infection (Fig. 9) (Love et al., 2004).

The role of FDG-PET in the evaluation of painful lower extremity joint prostheses has been extensively investigated (Van Acker et al., 2001; Zhuang et al., 2001; Chacko et al., 2002; Manthey et al., 2002; Vanquickenborne et al., 2003; Love et al., 2004; Stumpe et al., 2004).

Although initial reports suggested that FDG-PET could accurately identify the infected joint prosthesis, recent studies are less encouraging. FDG-PET is not capable of distinguishing the aseptically loosened, from the infected, prosthesis (Love et al., 2004; Stumpe et al., 2004). This is not surprising when one considers that inflammation, often intense, is present in both aseptic loosening and infection. In contrast to labeled leukocyte imaging, there is no preferential imaging of neutrophil mediated inflammatory processes with FDG. Thus, both aseptic loosening and infection are characterized by increased periprosthetic activity on FDG-PET studies. 


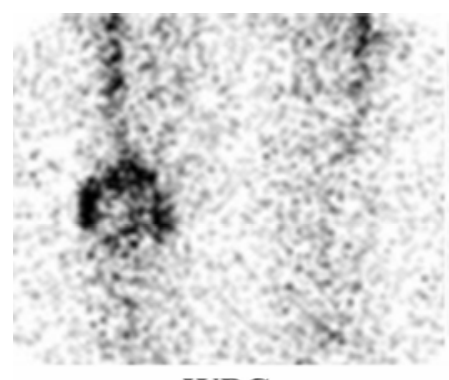

WBC

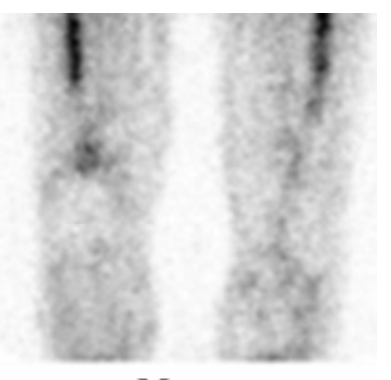

Marrow

Figure 9A - Infected right knee replacement. There is spatially incongruent distribution of periprosthetic activity on the labeled leukocyte and marrow images

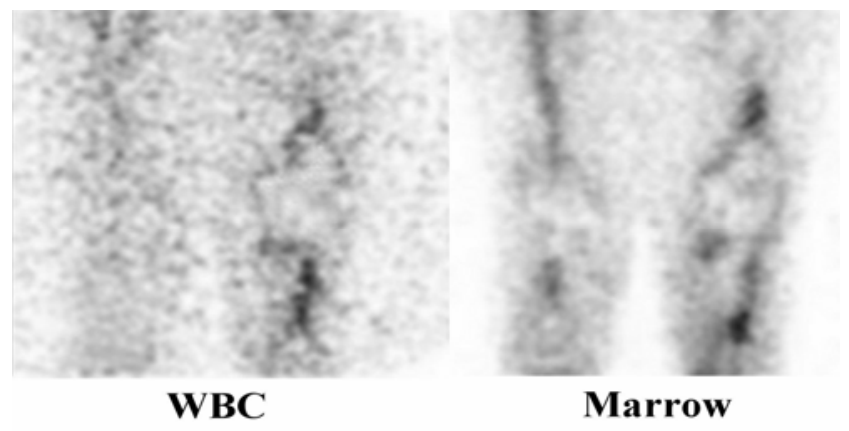

Figure 9B - Aseptically loosened left knee replacement. There is increased activity in the distal left femur and proximal left tibia on the labeled leukocyte image. The distribution of activity is the same on the marrow image and the combined study is negative for infection.

\section{Septic Arthritis}

Infectious organisms can reach the joint either through direct inoculation, hematogenous spread, or contiguous spread from an adjacent intraarticular site of osteomyelitis. The synovial lining of joints is highly vascular and lacks protective basement membrane. Entry of bacteria causes an influx of inflammatory cells and secretion of cytokines and proteolytic enzymes all geared towards elimination of organisms as well as neutralization of bacterial endotoxins. Unfortunately, these very same inflammatory responses also destroy synovium and cartilage. Thus, early diagnosis is of utmost importance.

Radionuclide studies are of limited value in the evaluation of septic arthritis. The classic presentation of acute arthritis on 3-phase bone scintigraphy consists of hyperperfusion and hyperemia of the joint, on early images, with increased activity limited to the articular surfaces of the involved bones on delayed images. This presentation is associated with both septic and aseptic arthritis. Osteomyelitis and acute arthritis, moreover, are not mutually exclusive, and bone scan findings consistent with septic arthritis do not exclude and can potentially mask an underlying osteomyelitis (Palestro, 1994). Neither gallium nor labeled leukocyte imaging reliably separate infectious from noninfectious arthritis. Labeled leukocyte imaging can be positive in rheumatoid arthritis, acute gouty arthritis, and pseudogout (Coleman et al., 1982; Uno et al., 1986; Palestro et al., 1990; Palestro et al., 1992). 


\section{CONCLUSIONS}

A wide range of radionuclide imaging modalities is available for the evaluation of clinically suspected musculoskeletal infection. Three- phase bone imaging accurately diagnoses infection in unviolated bone. Labeled leukocyte imaging is the radionuclide procedure of choice in cases of "complicating osteomyelitis", and is the imaging procedure of choice for prosthetic joint infection. Labeled leukocyte imaging also is useful in unsuspected diabetic pedal osteomyelitis, for monitoring response to treatment in these patients, and for evaluating the neuropathic joint. Gallium imaging is a useful adjunct to MRI in spinal infection. FDGPET likely will play an important role in spinal infections.

\section{RESUMO}

Estudos através de imagens com o uso de radionuclídeos são rotineiramente usadas para avaliar pacientes suspeitos de terem infecção músculo-esquelética. A imagem óssea em tridimensional é facilmente avaliável, relativamente de baixo custo, e muito precisa na localização de alterações ósseas. Imagem com leucócito marcado poderia ser usada nos casos de "osteomielite com complicações" tais como infecção prostética articular. Esse teste também é útil na não suspeita clinica de osteomielite associada ao pé diabético tanto quanto nas junções neuropáticas. É sempre necessário, por outro lado, realizar imagem complementar da medula óssea para aumentar a precisão da imagem com leucócito marcado. Em contraste com outras regiões no esqueleto, imagem com leucócito marcado não é útil para diagnosticar osteomielite da coluna vertebral. Até agora, o gálio é o radionuclídeo preferido para essa condição e é um adicional utilizável para imagem por ressonância magnética. FDG-PET igualmente será importante na avaliação de infecção músculo-esquelética, especialmente osteomielite espinhal, e pode substituir o gálio para esse propósito.

\section{REFERENCES}

Achong, D. M., Oates, E. (1994), The computergenerated bone marrow subtraction image: a valuable adjunct to combined In-111 WBC/Tc-99m in sulfur colloid scintigraphy for musculoskeletal infection. Clin Nucl Med., 19, 188-193.

Bell, G. I., Burant, C. F., Takeda, J., Gould, G. W. (1993), Structure and function of mammalian facilitative sugar transporters. J Biol Chem., 268: 19161-19164.

Chacko, T. K., Zhuang, H., Stevenson, K., Moussavian, B., Alavi A. (2002), The importance of the location of fluorodeoxyglucose uptake in periprosthetic infection in painful hip prostheses. Nucl Med Commun., 23, 851-855.

Cheung, A., Lachiewicz, P. F., Renner, J. B. (1997), The role of aspiration and contrast-enhanced arthrography in evaluating the uncemented hip arthroplasty. AJR Am J Roentgenol. 168, 1305-1309

Coleman, R.E., Samuelson, C., Bain, S. (1982), Imaging with Tc-99m MDP and Ga-67 citrate in patients with rheumatoid arthritis and septic arthritis. J Nucl Med., 23, 479-482.

De Winter, F., Van de Wiele, C., Vogelaers, D., De Smet, K., Verdonk, R., Dierckx, R. A. (2001), Fluorine-18 fluorodeoxyglucose-positron emission tomography: a highly accurate imaging modality for the diagnosis of chronic musculoskeletal infections. $J$ Bone Joint Surg., 83-A, 651-660.

De Winter, F., Gemmel, F., Van de Wiele, C., Poflijn, B., Uyttendaele, D., Dierckx, R. (2003), 18-fluorine fluorodeoxyglucose positron emission tomography for the diagnosis of infection in the postoperative spine. Spine. 28, 1314-1319.

De Winter, F., Gemmel, F., Van Laere, K., De Winter, O., Poflijn, B., Dierckx, R. A., Van de Wiele, C. (2004), 99mTc-ciprofloxacin planar and tomographic imaging for the diagnosis of infection in the postoperative spine: experience in 48 patients. Eur $J$ Nucl Med Mol Imaging., 31, 233-239.

Fehring, T. K., Cohen, B. (1996), Aspiration as a guide to sepsis in revision total hip arthroplasty. J Arthroplasty., 11, 543-547.

Feigin, D. S., Strauss, H. W., James, H. W. (1976), The bone marrow scan in experimental osteomyelitis. Skeletal Radiol., 1, 103-108.

Fineman, D. S., Palestro, C. J., Kim, C. K., Leedle, L. B., Vallabhajosula, S., Solomon, R. W., Goldsmith, S. J. (1989), Detection of abnormalities in febrile AIDS patients with In-111-labeled leukocyte and Ga67 scintigraphy. Radiology, 170, 677-680.

Gemmel, F., De Winter, F., Van Laere, K.Vogelaers, D., Uyttendaele, D., Dierckx, R. A. (2004), 99mTcciprofloxacin imaging for the diagnosis of infection in the postoperative spine. Nucl Med Commun., 25, 277-283. 
Gemmel, F., Dumarey, N., Palestro, C .J. (2006), Radionuclide imaging of spinal infections. Eur J Nucl Med Mol Imag., 33, 1226-1237.

Gratz S, Dorner J, Fischer U, Behr, T., Béhé, M., Altenvoerde, G., Meller, J., Grabbe, E., Becker, W. (2002), 18F-FDG hybrid PET in patients with suspected spondylitis. Eur J Nucl Med Mol Imaging., 29, 516-524.

Guhlmann, A., Brecht-Krauss, D., Suger, G., Glatting, G., Kotzerke, J., Kinzl, L., Reske, S. N. (1998), Chronic osteomyelitis: detection with FDG PET and correlation with histopathologic findings. Radiology, 206, 749-754.

Hadjipavlou, A., Cesani-Vazquez, F., VillaneuvaMeyer, J., Mader, J., Necessary, J., Crow, W., Jensen, R., Chajub, G. (1998), The effectiveness of gallium citrate $\mathrm{Ga} 67$ radionuclide imaging in vertebral osteomyelitis revisited. Am J Orthop., 27, 179-183.

Hoffer, P. (1980), Gallium: Mechanisms. J Nucl Med., 21, 282-285.

Joseph, T. N., Mujitaba, M., Chen, A. L., Maurer, S. L., Zukerman, J. D., Maldjian, C., Di Cesare, P. E. (2001), Efficacy of combined technetium-99m sulfur colloid/indium-111 leukocyte scans to detect infected total hip and knee arthroplasties. J Arthroplasty, 16, 753-758.

Kälicke, T., Schmitz, A., Risse, J., Arens, S., Keller, E., Hansis, M., Schmitt, O., Biersack, H. J., Grunwald, F. (2000), Flourine-18 fluorodeoxyglucose PET in infectious bone diseases: results of histologically confirmed cases. Eur J Nucl Med., 27, 524-528.

Keidar, Z., Militianu, D., Melamed, E., Bar-Shalom, R., Israel, O. (2005), The diabetic foot: initial experience with 18F-FDG PET/CT. J Nucl Med., 46, 444-449.

King, A. D., Peters, A. M., Stuttle, A. W., Lavender, J. P. (1990), Imaging of bone infection with labelled white blood cells: role of contemporaneous bone marrow imaging. Eur J Nucl Med., 17, 148-151.

Kubota, R., Yamada, S., Kubota, K., Ishiwata, K., Tamahashi, N., Ido, T. (1992), Intratumoral distribution of fluorine-18-fluorodeoxyglucose in vivo: high accumulation in macrophages and granulation tissues studied by microautoradiography. J Nucl Med., 33, 1972-1980.

Lachiewicz, P. F., Rogers, G. D., Thomason, H. C. (1996), Aspiration of the hip joint before revision total hip arthroplasty. Clinical and laboratory factors influencing attainment of a positive culture. J Bone Joint Surg. , 78, 749-754.

Lisbona, R., Derbekyan, V., Novales-Diaz, J., Veksler, A. (1993), Gallium-67 scintigraphy in tuberculous and nontuberculous infectious spondylitis. $\mathrm{J} \mathrm{Nucl}$ Med., 34, 853-859.

Love, C., Patel, M., Lonner, B. S., Tomas, M. B., Palestro, C. J. (2000), Diagnosing spinal osteomyelitis: A comparison of bone and gallium scintigraphy and magnetic resonance imaging. Clin Nucl Med., 25, 963-977.
Love, C., Tomas, M. B., Marwin, S. E., Pugliese, P. V., Palestro, C. J. (2001), Role of nuclear medicine in diagnosis of the infected joint replacement. RadioGraphics, 21, 1229-1238.

Love, C., Palestro, C. J. (2003), 99mTc-fanolesomab. Idrugs, 6, 1079-1085.

Love, C., Palestro, C. J. (2004), Radionuclide imaging of infection. J Nucl Med Tech., 32, 47-57.

Love, C., Marwin, S. E., Tomas, M. B., Krauss, E. S., Tronco, G. G., Bhargava, K. K., Nichols, K. J., Palestro, C. J. (2004), Diagnosing infection in the failed joint replacement: A comparison of coincidence detection fluorine-18 FDG and indium111-labeled leukocyte/technetium-99m-sulfur colloid marrow imaging. J Nucl Med., 45, 1864-1871.

Love, C., Tomas, M. B., Tronco, G. G., Palestro, C. J. (2005), Imaging infection and inflammation with ${ }^{18} \mathrm{~F}$ FDG-PET. RadioGraphics, 25, 1357-1368.

Manthey, N., Reinhard, P., Moog, F., Kneswitsch, P., Hahn, K., Tatsch, K. (2002), The use of $\left[{ }^{18} \mathrm{~F}\right]$ fluorodeoxyglucose positron emission tomography to differentiate between synovitis, loosening and infection of hip and knee prostheses. Nucl Med Commun., 23, 645-653.

Maurer, A. H., Chen, D. C. P., Camargo, E. E. (1981), Utility of three-phase skeletal scintigraphy in suspected osteomyelitis: Concise communication. $J$ Nucl Med., 22, 941-949.

Mochizuki, T., Tsukamoto, E., Kuge, Y., Kanegae, K., Zhao, s., Hikosaka, K., Hosokawa, M., Kohanawa, M., Tamaki, N. (2001), FDG uptake and glucose transporter subtype expressions in experimental tumor and inflammation models. J Nucl Med., 42, 1551-1555.

Modic, M. T., Feiglin, D. H., Piraino, D. W., Boumphrey, F., Weinstein, M. A., Duchesneau, P. M., Rehm, S. (1985), Vertebral osteomyelitis: assessment using MR. Radiology, 157, 157-166.

Mulamba, L'Ah, Ferrant, A., Leners, N., de Nayer, P., Rombouts, J. J., Vicent, A. (1983), Indium-111 leucocyte scanning in the evaluation of painful hip arthroplasty. Acta Orthop Scand., 54, 695-697.

Newman, L. G., Waller, J., Palestro, C. J., Schwartz, M., Klein, M. J., Hermann, G., Harrington, E., Harrington, M., Roman, S. H., Stagnaro-Green, A. (1991), Unsuspected osteomyelitis in diabetic foot ulcers: diagnosis and monitoring by leukocyte scanning with indium In 111 oxyquinoline. JAMA, 266, 1246-1251.

Newman, L. G., Waller, J., Palestro, C. J., Hermann, G., Klein, M. J., Schwartz, M., Harrington, E., Harrington, M., Roman, S. H., Stagnaro-Green, A. (1992), Leukocyte scanning with ${ }^{111}$ In is superior to magnetic resonance imaging in the diagnosis of clinically unsuspected osteomyelitis in diabetic foot ulcers. Diabetes Care, 15, 1527-1530. 
Paik, J. Y., Lee, K. H., Choe, Y. S., Choi, Y., Kim, B. T. (2004), Augmented ${ }^{18}$ F-FDG uptake in activated monocytes occurs during the priming process and involves tyrosine kinases and protein kinase C. $\mathrm{J} \mathrm{Nucl}$ Med., 45, 124-128.

Palestro, C. J., Kim, C. K., Swyer, A. J., Capozzi, J. D., Solomon, R. W., Goldsmith, S. J. (1990), Total-hip arthroplasty: periprosthetic indium-111-labeled leukocyte activity and complementary technetium99 m-sulfur colloid imaging in suspected infection. $J$ Nucl Med., 31, 1950-1955.

Palestro, C. J., Vega, A., Kim, C. K., Swyer, A. J., Goldsmith, S. J. (1990), Appearance of acute gouty arthritis on indium-111 Labeled leukocyte scintigraphy. J Nucl Med., 31, 682-687.

Palestro, C., Swyer, A., Kim, C., Goldsmith, S. (1991), Tuberculous lymphadenitis: In-111 leukocyte and Ga-67 imaging. Clin Nucl Med., 16, 857-858.

Palestro, C. J., Swyer, A. J., Kim, C. K. et al. (1991), Infected knee prosthesis: diagnosis with In-111 leukocyte, Tc-99m sulfur colloid, and Tc-99m MDP imaging. Radiology, 179:645-648.

Palestro, C. J., Kim, C. K., Swyer, A. J., Goldsmith, S. J. (1991), Radionuclide diagnosis of vertebral osteomyelitis: indium-111-leukocyte and technetium99m-methylene diphosphonate bone scintigraphy. $J$ Nucl Med., 32, 1861-1865.

Palestro, C. J., Goldsmith, S. J. (1992), In-111 labeled leukocyte imaging in a case of pseudogout. Clin Nucl Med., 17, 366-367.

Palestro, C. J., Schultz, B. L., Horowitz, M., Swyer, A. J. (1992), Indium-111 leukocyte and gallium-67 imaging in acute sarcoidosis: Report of two patients. J Nucl Med., 33, 2027-2029.

Palestro, C. J., Roumanas, P., Swyer, A. J., Kim, C. K., Goldsmith, S. J. (1992), Diagnosis of musculoskeletal infection using combined In-111 labeled leukocyte and Tc-99m SC marrow imaging. Clin Nucl Med., 17, 269-273.

Palestro, C. J. (1994), The current role of gallium imaging in infection. Semin Nucl Med., 24, 128-141

Palestro, C. J. (1994), Musculoskeletal infection. InNuclear Medicine Annual, ed. L.M. Freeman. Lippincott Williams and Wilkins, Philadelphia, pp. 91-119.

Palestro, C. J., Torres, M. A. (1997), Radionuclide imaging in orthopedic infections. Semin Nucl Med., 27, 334-345.

Palestro, C. J., Mehta, H. H., Patel, M., Freeman, S. J., Harrington, W. N., Tomas, M. B., Marwin, S. E. (1998), Marrow versus infection in the Charcot joint: Indium-111 leukocyte and technetium-99m sulfur colloid scintigraphy. J Nucl Med., 39, 346-350.

Palestro, C. J., Tomas, M. B. (2000), Scintigraphic evaluation of the diabetic foot. In: Nuclear Medicine Annual. Ed. L.M. Freeman. Lippincott Williams and Wilkins, Philadelphia, pp. 143-172.
Palestro, C. J., Love, C., Tronco, G. G., Tomas, M. B., Rini, J. N. (2006), Combined labeled leukocyte and technetium-99m sulfur colloid marrow imaging for diagnosing musculoskeletal infection: principles, technique, interpretation, indications and limitations. RadioGraphics, 26, 859-870.

Pauwels, E. K. J., Ribeiro, M. J., Stoot, J. H. M. B., McCready, V. R., Bourguignon, M., Maziere, B. (1998), FDG accumulation and tumor biology. Nucl Med Biol., 25, 317-322.

Sarda, L., Saleh-Mghir, A., Peker, C., Meulemans, A., Cremieux, A. C., Le Guludec, D. (2002), Evaluation of $(99 \mathrm{~m}) \mathrm{Tc}$-ciprofloxacin scintigraphy in a rabbit model of Staphylococcus aureus prosthetic joint infection. J Nucl Med., 43, 239-245.

Schauwecker, D. S. (1992), The scintigraphic diagnosis of osteomyelitis. Am J Roentgenol., 158, 9-18.

Seabold, J. E., Nepola, J. V., Marsh, J. L., Hawes, D. R., Justin, E. P., Ponto, J. A., Petit, W. A., el-Khoury, G. Y., Kirchner, P. T. (1991), Postoperative bone marrow alterations: potential pitfalls in the diagnosis of osteomyelitis with In-111-labeled leukocyte scintigraphy. Radiology, 180, 741-747.

Schiesser, M., Stumpe, K. D. M., Trentz, O., Kossmann, T., Von Schulthess, G. K. (2003), Detection of metallic implant-associated infections with FDG PET in patients with trauma: Correlation with microbiologic results. Radiology, 226, 391-398.

Sonmezoglu, K., Sonmezoglu, M., Halac, M., Akgun, I., Turkmen, C., Onsel, C., Kanmaz, B., Solanki, K., Britton, K. E., Zulú, I. (2001), Usefulness of 99mTcciprofloxacin (Infecton) scan in diagnosis of chronic orthopedic infections: Comparative study with 99mTc-HMPAO leukocyte scintigraphy. $J \mathrm{Nucl}$ Med., 42, 567-574.

Stumpe, K. D. M., Zanetti, M., Weishaupt, D., Hodler, J., Boos, N., Von Schulthess, G. K. (2002), FDG positron emission tomography for differentiation of degenerative and infectious endplate abnormalities in the lumbar spine detected on MR imaging. Am J Roentgenol., 179, 1151-1157.

Stumpe, K. D. M., Notzli, H., Zanetti, M., Kamel, E. M., Hany, T. F., Görres, G. W., von Schultness, G. K., Hodler, J. (2004), FDG-PET in the differentiation of infection and aseptic loosening in patients with total hip replacements: comparison with conventional radiographs and three-phase bone scintigraphy. Radiology, 231, 333-341

Sugawara, Y., Braun, D., Kison, P., Russo, J., Zasadny, K. R., Wahl, R. L. (1998), Rapid detection of human infections with fluorine-18 fluorodeoxyglucose and positron emission tomography: preliminary results. Eur J Nucl Med., 25, 1238-1243.

Uno, K., Matsui, N., Noria, K., Suguru, T., Kitakata, Y., Uchiyama, G., Miyoshi, T., Uematsu, S., Inoue, S., Arimizu, N. (1986), Indium-111 leukocyte imaging in patients with rheumatoid arthritis. $\mathrm{J} \mathrm{Nucl}$ Med., 27, 339-344. 
Van Acker, F., Nuyts, J., Maes, A., Vanquickenborn, B., Stuyck, J., Bellemans, J., Vleugels, S., Bormans, G., Mortelmans, L. (2001), FDG-PET, ${ }^{99 \mathrm{~m}} \mathrm{Tc}$ HMPAO white blood cell SPET and bone scintigraphy in the evaluation of painful total knee arthroplasties. Eur J Nucl Med., 28, 1496-1504.

Vanquickenborne, B., Maes, A., Nuyts, J., Van Acker, F., Stuyck, J., Mulier, M., Verbruggen, A., Mortelmans, L. (2003), The value of ${ }^{18}$ FDG-PET for the detection of infected hip prosthesis. Eur $\mathrm{J} \mathrm{Nucl}$ Med Mol Imaging., 30, 705-715.

Vicente, A. M. G., Solis, S. R., Castrejón, A. S., Garcia, V. M. P., Rubio, M. P. T., Marina, S. R., Romera, M. C. (2005), Scintigraphic diagnosis of infectious complications in renal failure patients undergoing hemodialysis, continuous laboratory peritoneal dialysis or renal transplant. Braz Arch Biol Technol., 48, 97108.

Wrobel, J. S., Connolly, J. E. (1998), Making the diagnosis of osteomyelitis: the role of prevalence. $J \mathrm{Am}$ Podiatr Med Assoc., 88, 337-343.
Zhuang, H., Duarte, P. S., Pourdehnad, M., Maes, A., Van Arcker, F., Shnier, D., Garino, J. P., Fitzgerald, R. H., Alavi, A. (2001), The promising role of ${ }^{18} \mathrm{~F}$ FDG PET in detecting infected lower limb prosthesis implants. J Nucl Med., 42, 44-48.

Zhuang, H., Alavi, A. (2002), 18-Fluorodeoxyglucose positron emission tomographic imaging in the detection and monitoring of infection and inflammation. Semin Nucl Med., 32, 47-59.

Zhuang, H., Sam, J., Chacko, T., Duarte, P. S., Hickeson, M., Feng, O., Nakhoda, K. Z., Guan, L., Reich, P., Altimari, S. M., Alavi, A. (2003), Rapid normalization of osseous FDG uptake following traumatic or surgical fractures. Eur J Nucl Med Mol Imaging., 30, 1096-1103. 